\title{
Peer Review of "Technologies to Support Assessment of Movement During Video Consultations: Exploratory Study"
}

Immanuel Victor George, MSN, PGDANP

NHS WWL Foundation Trust, Wigan, United Kingdom

Related Articles:

Preprint: https://preprints.jmir.org/preprint/30233

Authors' Response to Peer-Review Reports: https://med.jmirx.org/2021/3/e32248/

Published Article: https://med.jmirx.org/2021/3/e30233/

(JMIRx Med 2021;2(3):e32263) doi: 10.2196/32263

\section{KEYWORDS}

tele-rehabilitation; video-consultations; assessment of movement; eHealth; technology; desktop robots; wide-angle webcams; physical health; rehabilitation; remote; assessment; assistive technology; evaluation; framework; webcam; telehealth; robots

This is a peer-review report submitted for the paper

"Technologies to Support Assessment of Movement During Video Consultations: Exploratory Study.”

\section{Round 1 Review}

\section{General Comments}

This paper [1] is an exploratory study on technologies to support video consultations assessing movement. It is not clear whether it explored the technology itself or the process of using various technologies.

\section{Specific Comments}

\section{Major Comments}

1. It is not clear why 4 specific devices were chosen and there is no explanation of the most widely used software. Is it technology or device exploration?

2. I was unable to identify clearly whether the hypothetical patients were physiotherapists or family members. Were the hypothetical patients briefed on what they should present for inference, or was the clinical condition identified as they presented?

3. How many hypothetical patients took part in the study?

\section{Minor Comments}

4. The experiences of the hypothetical patients were not detailed.

\section{Conflicts of Interest}

None declared.

\section{Reference}

1. Jones RB, Hubble S, Taylor L, Gunn H, Logan A, Rowland T, et al. Technologies to support assessment of movement during video consultations: exploratory study. JMIRx Med 2021 Sep;2(3):e30233 [FREE Full text] [doi: 10.2196/30233]

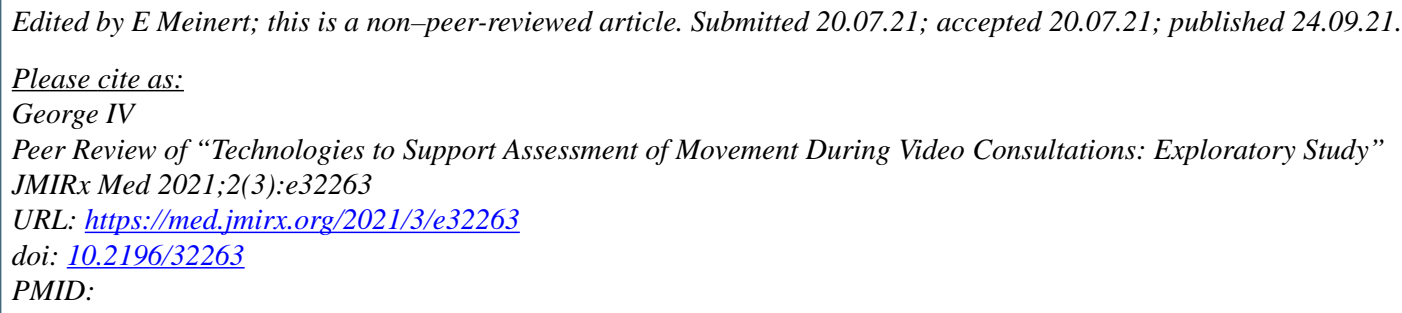


which permits unrestricted use, distribution, and reproduction in any medium, provided the original work, first published in JMIRx Med, is properly cited. The complete bibliographic information, a link to the original publication on https://med.jmirx.org/, as well as this copyright and license information must be included. 